periphlebitis induced by a bacterial infection may cause PVT in cirrhosis patients as a consequence of the slow portal flow of these patients. At present, better sanitary conditions of the population might play an important role in the decreased frequency of that complication. ${ }^{1}$

Other causes of PVT in non-cirrhotic adults include abdominal trauma, pancreatitis, intraabdominal sepsis, splenectomy, porta-caval shunts, or an associated hypercoagulability state (pregnancy, myelofibrosis, tumours). ${ }^{5}$ In many cases, the aetiology is unknown. ${ }^{6}$

In our patient, PVT associated with cirrhosis and infection of the portal area by $C$. albicans, led us to consider the possibility that a systemic infection by $S$. milleri had induced a periphlebitis, which in turn would act as a trigger for PVT. Infection by $C$. albicans would therefore be a superadded infection of the thrombus; However, the good response of the patient once treated with amphotericin B with further elimination of the yeast from the portal area, as proven by fine needle aspiration puncture, together with the recanalization of the superior mesenteric vein, led us to suspect that the most important factor maintaining PVT was indeed the associated candidiasis.

We think that though the incidence of PVT of infectious origin is low, when PVT is demonstrated in the absence of tumour, it is wise to perform a fine needle aspiration puncture (given the low incidence rate of complications of this procedure in our experience) with the aim to rule out an overimposed infection which is potentially treatable with specific antibiotic therapy.

\title{
References
}

1. Okuda, K., Ohnishi, K., Kimura, K. et al. Incidence of portal vein thrombosis in liver cirrhosis. An angiographic study in 708 patients. Gastroenterology 1985, 89: 279-286.

2. Sherlock, S. Diseases of the Liver and Biliary System, 8th ed. Blackwell Scientific Publications, London, 1989, pp. 176-178.

3. Webb, L.J. \& Sherlock, S. The aetiology, presentation and natural history of extra-hepatic portal venous obstruction. $Q J$ Med 1979, NS XLVIII: 627-639.

4. Hunt, A.H. \& Whittard, B.R. Thrombosis of the portal vein in the cirrhosis hepatis. Lancet 1954, i: 281-284.

5. Zakim, D. \& Boyer, T.D. Hepatology, 2nd ed. W.B. Saunders Company, Philadelphia, 1990, p. 585.

6. Sahni, P., Pande, G.K. \& Nundy, S. Extrahepatic portal vein obstruction. Br J Surg 1990, 77: 1201-1202.

\section{Keloid of the penis after circumcision}

\author{
D.J. Warwick and W.A. Dickson
}

Welsh Centre for Plastic Surgery, St Lawrence Hospital, Chepstow, Gwent, UK

\section{Summary: We report what we believe is the first documented case of keloid formation on the penis following circumcision.}

\section{Introduction}

Keloid formation is a well-recognized complication of both surgical and traumatic skin wounds. However, this has not, as far as we know, been reported after the common procedure of circumcision, even in those otherwise predisposed to keloid.

Correspondence: D.J. Warwick, F.R.C.S

Accepted: 21 July 1992

\section{Case report}

A 10 year old coloured boy from Sierra Leone underwent a routine circumcision for cultural reasons. The procedure was uneventful and there were no early complications; however, he presented 2 years later with pronounced keloid formation around the base of the glans (Figure 1). He complained of embarrassment and pruritis. He had a previous keloid following a traumatic wound to his axilla but there was no family history of keloid formation. 


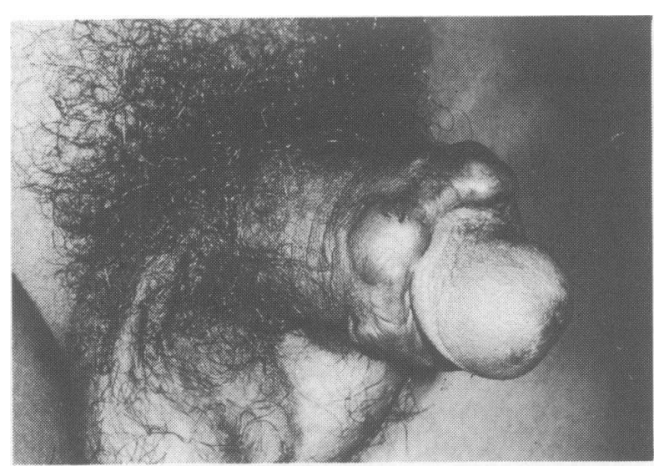

Figure 1 Keloid of the penis.

The penile keloid was treated by serial injections of intradermal triamcinolone under general anaesthetic. After four injections there was an appreciable reduction in both the size of the lesion and the itching.

\section{Discussion}

Keloid of the genitalia is exceedingly rare. It is intriguing that keloid has never been observed after

\section{References}

1. Brown, D. Hypospadias. Postgrad Med J 1949, 25: 367-375.

2. Crockett, D.J. Regional keloid susceptibility. Br J Plastic Surg 1964, 17: 245-253.

3. Parsons, R.W. A case of keloid of the penis. Plastic Reconstruct Surg 1966, 37: 431-432. the common procedure of circumcision. Denis Browne $^{1}$ stated that the skin of the penis 'never forms keloid' and Crockett ${ }^{2}$ found no example in a review of 250 Sudanese natives. In fact, two cases of penile keloid do exist in the literature. One case ${ }^{3}$ developed after surgical removal of a traumatic cyst on the shaft in an eight-year old Negro boy who, incidentally, had previously been circumcized without this complication. The second case ${ }^{4}$ followed a major laceration and subsequent burn to the shaft and scrotum of a 44 year old Caucasian.

Local pressure or irradiation are recognized methods of treating keloid ${ }^{5}$ but these techniques would be inappropriate in this anatomical area: it is impractical to apply firm and sustained compression, and irradiation is undesirable in such proximity to the testes. Excision is unreliable as recurrence and even exacerbation is likely to occur.

Local steroid injection is often effective in treating keloids, although its action is not fully understood. The triamcinolone is injected directly into the lesion in an amount sufficient to cause blanching; the injection can be repeated regularly although after a few doses there is a significant risk of local fat and skin atrophy.

4. Kormoczy, I. Enormous keloid (?) on the penis. Br J Plastic Surg 1978, 31: 268-269.

5. McGregor, I.A. Fundamental Techniques of Plastic Surgery, 8th ed. Churchill Livingstone, Edinburgh, 1989, pp. 18-22.

\title{
Resolution of danazol-induced cholestasis with S-adenosylmethionine
}

\author{
Gary P. Bray, J. Michael Tredger and Roger Williams
}

Institute of Liver Studies, King's College Hospital School of Medicine and Dentistry, Denmark Hill, London SE5 $8 R X, U K$

\begin{abstract}
Summary: In a case of danazol-induced cholestasis, the anti-cholestatic agent S-adenosylmethionine was given intravenously for 3 weeks and then orally for 6 weeks. This was well tolerated and led to prompt resolution of both jaundice and associated renal impairment.
\end{abstract}

